\title{
Potensi Pola Perjalanan Wisata Gastronomi di Kota Cirebon
}

\author{
Rakhmat Alief Marthaputra1, Dewi Turgarini², Woro Priatini3 \\ 1,2,3 Manajemen Industri Katering, Fakultas Pendidikan Ilmu Pengetahuan Sosial, \\ Universitas Pendidikan Indonesia, Jl Dr. Setiabudhi No: 229, Bandung, Indonesia \\ 12RakhmatAliefMarthaputra@student.upi.edu, ${ }^{2}$ dewiturgarini@upi.edu, ${ }^{3}$ woro.priatini@upi.edu
}

\begin{tabular}{l|l|l} 
Received: Mei, 2021 & Accepted: Mei, 2021 & Published: June, 2021
\end{tabular}

\begin{abstract}
Cirebon has a diverse tourism potential, including historical tourism, pilgrimage tourism, cultural tourism, and gastronomic tourism. The existence of three sultanates, as well as the pilgrimage destination of Sunan Gunung Jati, contributed to the wealth of tourism. The city also has a plethora of gastronomic tourism, which is heavily influenced by the historical tourism of the three sultanates. Currently, the city is not supported by gastronomic travel patterns that its stakeholders have socialized. The author employed a qualitative research method with a descriptive approach. Data for this study were gathered through observation and interviews.
\end{abstract}

Keywords: cirebon, travel patterns, gastronomy

\begin{abstract}
Abstrak
Kota Cirebon adalah kota yang memiliki potensi wisata yang beragam baik wisata sejarah, wisata ziarah, wisata budaya dan juga wisata gastronomi. Kekayaan wisata itu ditunjang dengan eksistensi tiga kesultanan, dan destinasi wisata ziarah Sunan Gunung Jati. Kota ini pun memiliki kekayaan wisata gastronomi yang kental diwarnai keberadaan wisata sejarah dari ketiga kesultanan tersebut. Saat ini Kota ini belum didukung pola perjalanan wisata gastronomi yang disosialisasikan oleh para stakeholdernya. Metode penelitian yang digunakan oleh penulis adalah metode penilitian kualitatif dengan pendekatan deskriptif. Penelitian ini menggunakan teknik observasi dan wawancara untuk mengumpulkan data.
\end{abstract}

Kata Kunci: cirebon, pola perjalanan, gastronomi

\section{PENDAHULUAN}

Pariwisata Indonesia saat ini sedang mengalami perkembangan yang signifikan, dapat dibuktikan dalam data statistik kunjungan wisatawan yang di unggah oleh Kementerian Pariwisata Indonesia yang meliputi beberapa kegiatan pariwisata yaitu wisata kuliner, wisata budaya, wisata alam, wisata belanja, dan wisata religi, 
pengembangan sektor wisata tidak hanya di kota-kota besar dalam hal ini pemerintah mulai mengembangkan wisata dari setiap daerah yang ada di Indonesia, hal ini dilakukan agar pariwisata di Indonesia merata dan dapan membantu perkembangan daerah tersebut. Cirebon adalah salah satu kota di Jawa Barat yang berada di ujung timur yang berbatasan langsung dengan jawa tengah. Dapat dilihat dari data yang didapat dari www.bps.go.id (web resmi Badan Pusat Statistika Jawa Barat) bahwa Cirebon (Kota Cirebon dan Kabupaten Cirebon) memiliki data wisatawan seperti yang tertera, Kota Cirebon dikunjungi sebanyak 1.423 wisatawan mancanegara dan 1.354 .722 wisatawan lokal, sedangkan Kabupaten Cirebon memiliki data 0 wisatawan mancanegara dan 644.244 wisatawan lokal.

Kota Cirebon atau kota yang biasa dijuluki dengan kota udang ini memiliki berbagai destinasi pariwisata yang sedang dalam proses pengembangan oleh pemerintah daerah. Cirebon terkenal dengan destinasi wisata religi dan budaya, terdapat tiga kesultanan besar yang membantu menopang pariwisata yang ada di Cirebon. Cirebon memiliki beberapa destinasi pariwisata seperti Keraton Kesepuhan, Makam Sunan Gunung Jati, Goa Sunyaragi, dan Cirebon memiliki berbagai destinasi wisata kuliner khas antara lain, Nasi Jamblang, Empal Gentong, dan Tahu Gejrot tidak hanya itu, Cirebon memiliki destinasi wisata gastronomi khas makanan kesultanan Cirebon yaitu Sega Bogana yang ada di Keraton Kacirebonan. Dilihat dari banyaknya destinasi pariwisata dan potensi wisata gastronomi di wilayah Cirebon, memungkinkan untuk dibuat pola perjalanan pariwisata yang terkordinasi dengan baik untuk meningkatkan potensi pariwisata di wilayah Kota Cirebon. Menurut Turgarini (2018:18) pariwisata gastronomi dapat meningkatkan pendapatan daerah tersebut dengan menjadikan makanan khas daerah tersebut menjadi destinasi wisata bagi daerah tersebut.

Dibalik keberagaman kuliner yang ada di Indonesia, setiap daerah memiliki kekayaan resep menu, rempah, dan cerita dibalik hidangan makanannya sebagai potensi kekayaan Indonesia. Gastronomi seringkali dikaitkan dengan wisata kuliner oleh masyarakat Indonesia. Sejatinya gastronomi dan kuliner adalah hal yang berbeda. Disimpulkan dari beberapa teori diatas pariwisata gastronomi dapat menjadi salah satu pendapatan daerah dan dapat meningkatkan kesejahteraan bagi masyarakat yang berada di sekitar destinasi wisata, kota cirebon memiliki banyak makanan khas yang sangat sulit dijumpai di daerah lain, hal tersebut menjadikan nilai tersendiri bagi kota cirebon, dengan adanya pola perjalanan, dapat mensinergikan kegiatan wisata gastronomi di Kota Cirebon dengan stakeholder pariwisata di Kota Cirebon, agar lebih terkelola dengan baik dan meningkatkan pendapatan daerah Kota Cirebon itu sendiri.

Hal ini penting dilakukan untuk mengembangkan potensi gastronomi yang ada di Kota Cirebon dan untuk kelancaran program destinasi wisata gastronomi yang ada di Kota Cirebon yang sudah memiliki kekayaan gastronomi yang melimpah sehingga dapat menjadi lebih baik. Penelitian ini bertujuan untuk mengidentifikasi karakteristik wisatawan Kota Cirebon, Daya tarik wisata Kota Cirebon, Makanan lokal di Kota Cirebon, Pemangku kepentingan dalam pengembangan wisata Gastronomi di Kota Cirebon dan juga untuk mengetahui rancangan pola perjalanan wisata Gastronomi di Kota Cirebon.

\section{METODE PENELITIAN}

Metode yang digunakan dalam penelitian ini adalah metode kualitatif yaitu suatu penelitian secara mendalam hal ini dilakukan peneliti peneliti memerlukan data yang terbilang khusu dan memerlukan informasi yang mendalam. Meleong, (2007:5) mengatakan bahwa penilitian kualitatif merupakan penelitan yang memanfaatkan wawancara sebagai cara untuk menelaah dan memahami sikap, pandangan, perasaan dan perilaku individu atau kelompok. 
Pendekatan dalam penelitian ini menggunakan pendekatan analisis deskriptif Wardiyanta (2006;5) mengatakan bahwa penelitian deskriptif adalah penelitian yang memiliki tujuan membuat deskripsi atas fenomena sosial atau fenomena alam yang sistematis akurat dan faktual. Selain itu penelitian deskriptif ini juga sering kali digunakan untuk menjawab pertanyaan berbagai peristiwa atau fenomena di masyarakat.

Objek Penelitian ini dilakukan di Kota Cirebon adapun yang diteliti dalam penelitian ini adalah karakteristik wisatawan di Kota Cirebon, dan Peran Stakeholder. Dalam penelitian ini teknik sampel yang digunakan adalah teknik non probability sampling.

Teknik sampling non probability sampling adalah teknik yang tidak memberi peluang atau kesempatan yang sama bagi setiap unsur atau anggota populasi untuk dipilih menjadi sample (Sugiyono, 2015:840). , sampel yang akan diambil dalam penelitian ini adalah sebanyak 96,04 orang. Untuk memudahkan perhitungan maka akan dibulatkan ke atas menjadi 100 orang responden.

Populasi dari penelitian ini adalah seluruh wisatawan lokal yang akan mengunjungi Kota Cirebon yang berusia lebih dari 17 tahun yang berasal dari daerah dalam dan luar Kota Cirebon dan pernah mengunjungi Kota Cirebon sebelumnya. Teknik pengumpulan data dalam penelitian ini menggunakan metode wawancara, kusioner, observasi, studi dokumentasi dan studi literatur.

\subsection{Uji Validitas}

Tabel 1: Hasil Rekapitulasi besar nilai valuasi [sumber: Hasil olah data SPSS 24, tahun 2020]

\begin{tabular}{ccccc}
\hline $\begin{array}{c}\text { No } \\
\cdot\end{array}$ & $\begin{array}{c}\text { Variab } \\
\text { el }\end{array}$ & $\mathbf{r}_{\text {hitung }}$ & $\mathbf{r}_{\text {tabel }}$ & kriteria \\
\hline 1 & $\mathrm{Q} 1$ & 0,566 & 0,349 & VALID \\
2 & $\mathrm{Q} 2$ & 0,806 & 0,349 & VALID \\
3 & $\mathrm{Q} 3$ & 0,719 & 0,349 & VALID \\
4 & $\mathrm{Q} 4$ & 0,665 & 0,349 & VALID \\
5 & $\mathrm{Q} 5$ & 0,649 & 0,349 & VALID \\
6 & $\mathrm{Q} 6$ & 0,653 & 0,349 & VALID \\
7 & $\mathrm{Q} 7$ & 0,749 & 0,349 & VALID \\
8 & $\mathrm{Q} 8$ & 0,781 & 0,349 & VALID \\
9 & $\mathrm{Q} 9$ & 0,599 & 0,349 & VALID \\
10 & $\mathrm{Q} 10$ & 0,725 & 0,349 & VALID \\
11 & $\mathrm{Q} 11$ & 0,615 & 0,349 & VALID \\
12 & $\mathrm{Q} 12$ & 0,506 & 0,349 & VALID \\
\hline
\end{tabular}

\subsection{Uji Reabilitas}

Tabel 2: Hasil Uji Reabilitas Instrumen [sumber: Hasil olah data SPSS 24, tahun 2020]

\begin{tabular}{cc}
\hline $\begin{array}{c}\text { Cronbach's } \\
\text { Alpha }\end{array}$ & $\begin{array}{c}\text { N of } \\
\text { Items }\end{array}$ \\
\hline 0,876 & 12 \\
\hline
\end{tabular}




\section{HASIL DAN PEMBAHASAN}

3.1 Deskripsi Data Hasil Kuisioner Karakteristik Responden Berdasarkan Jenis Kelamin

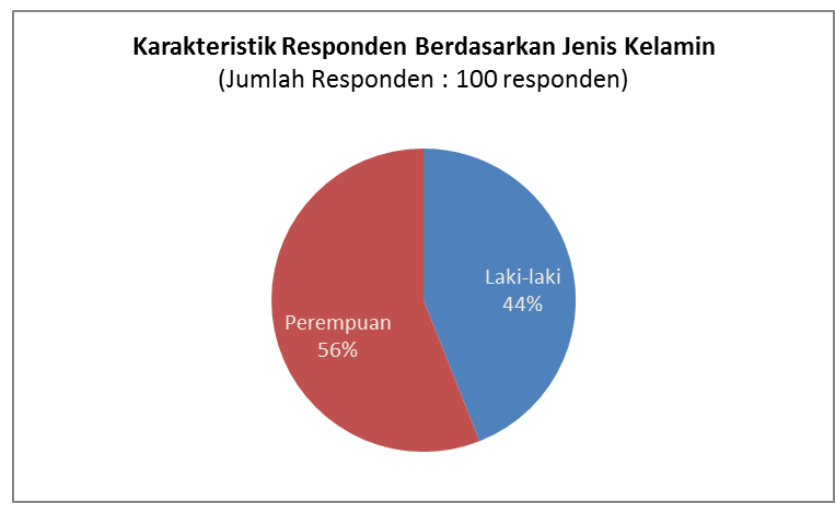

Gambar 1. Karakteristik Responden Berdasarkan Jenis Kelamin [Sumber: Penulis, Data diolah 2020]

Karakteristik wisatawan yang berkunjung ke Kota Cirebon berdasarkan jenis kelamin. Persentase terbesar wisatawan berkunjung ke Kota Cirebon adalah berjenis kelamin perempuan yaitu sebesar 56\%.

\section{Karakteristik Responden Berdasarkan Usia}

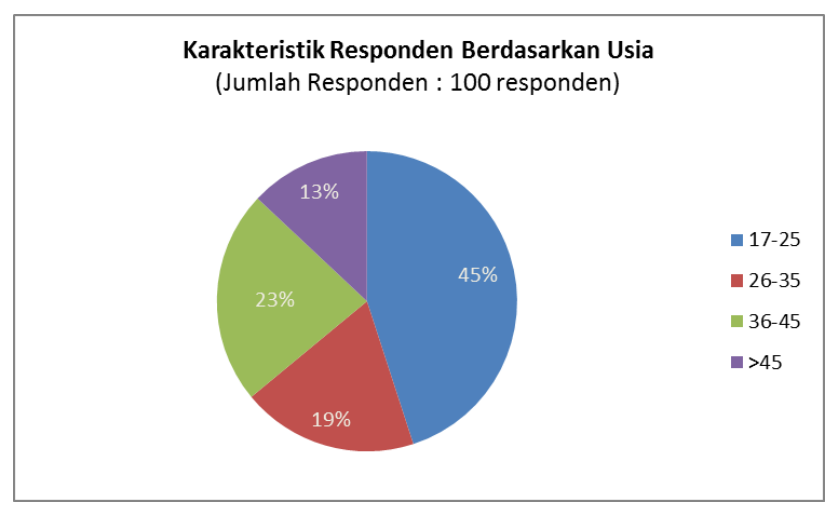

Gambar 2. Karakteristik Responden Berdasarkan Usia [Sumber: Penulis, Data diolah 2020]

Karakteristik wisatawan berdasarkan rentang usia. Persentase terbesar adalah 1725 tahun yaitu sebanyak 45\%. Hal tersebut menunjukkan bahwa wisatawan yang berkunjung ke Kota Cirebon berasal dari berbagai usia, namun rata-rata pengunjung ada pada rentang usia 17-25 tahun. 


\section{Karakteristik Responden Berdasarkan Daerah Asal}

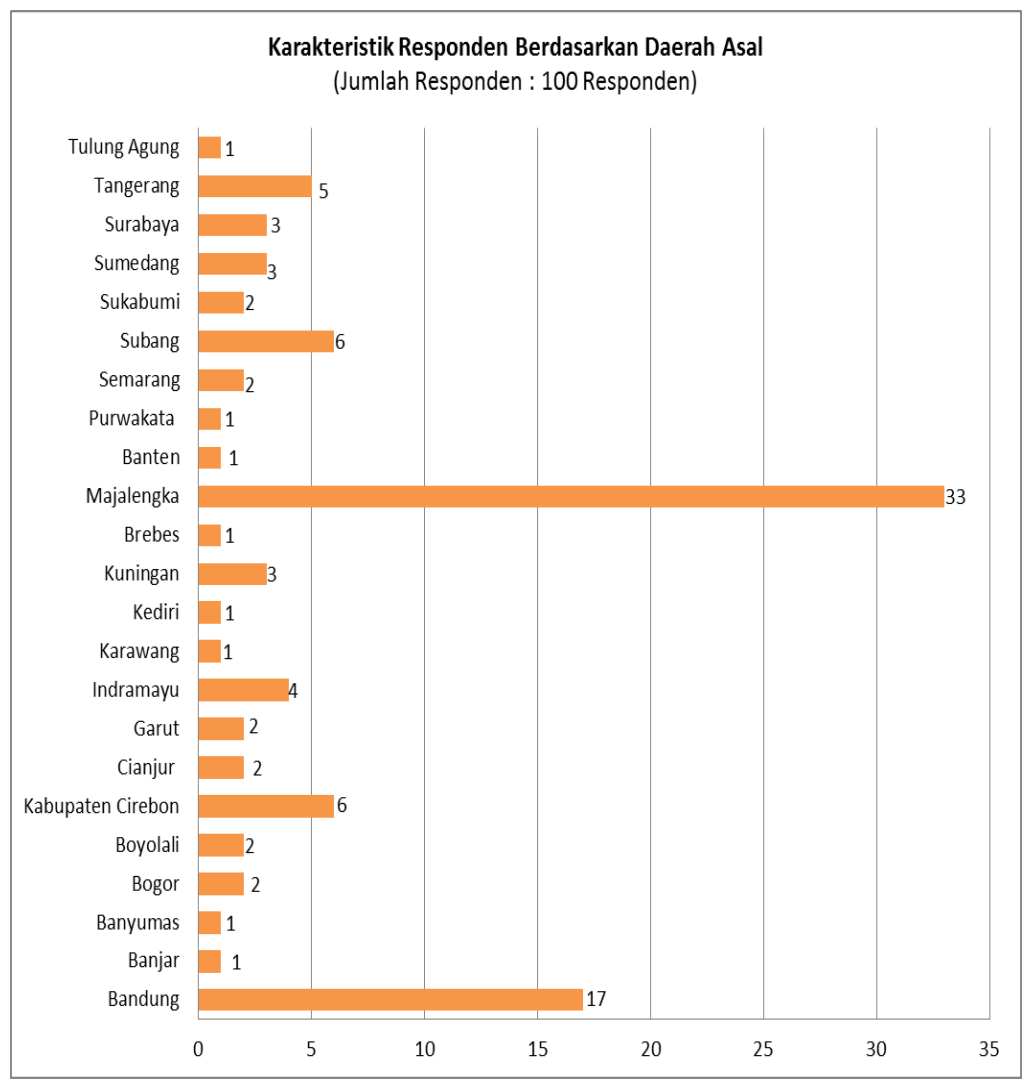

Gambar 3. Karakteristik Responden Berdasarkan Daerah Asal [Sumber: Penulis, Data diolah 2020]

Karakteristik wisatawan berdasarkan rentang usia. Persentase terbesar adalah 1725 tahun yaitu sebanyak 45\%. Hal tersebut menunjukkan bahwa wisatawan yang berkunjung ke Kota Cirebon berasal dari berbagai usia, namun rata-rata pengunjung ada pada rentang usia 17-25 tahun.

\section{Karakteristik Responden Berdasarkan Jenis Pekerjaan}

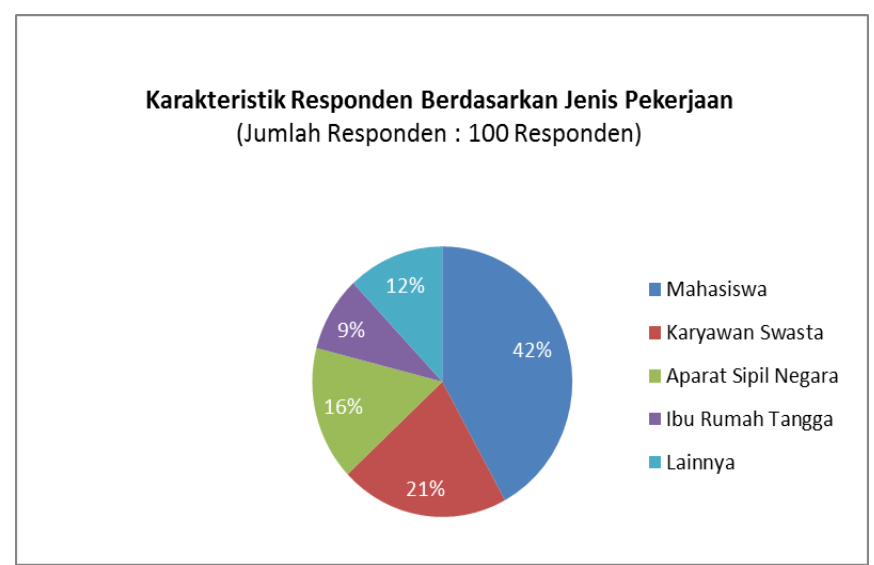

Gambar 4. Karakteristik Responden Berdasarkan Jenis Pekerjaan

[Sumber: Penulis, Data diolah 2020] 
Karakteristik wisatawan yang berkunjung ke Kota Cirebon berdasarkan jenis pekerjaan. Data menunjukkan bahwa wisatawan berasal dari berbagai jenis pekerjaan. Namun, sebagain besar wisatawan adalah berstatus sebagai mahasiswa yaitu sebanyak $42 \%$.

\section{Karakteristik Responden Berdasarkan Pendidikan Terakhir}

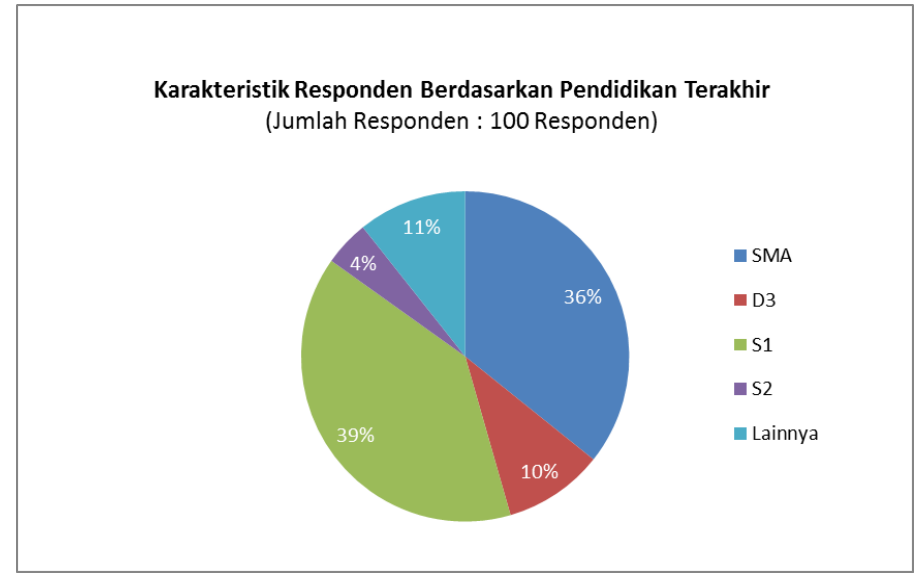

Gambar 5.Karakteristik Responden Berdasarkan Pendidikan Terakhir [Sumber: Penulis, Data diolah 2020]

Karakteristik wisatawan Kota Cirebon berasal dari berbagai pendidikan terakhir yang ditempuh. Wisatawan yang mendominasi yaitu berpendidikan terakhir S1 sebanyak $44 \%$ dan SMA sebanyak 40\%.

\section{Karakteristik Responden Berdasarkan Pendapatan}

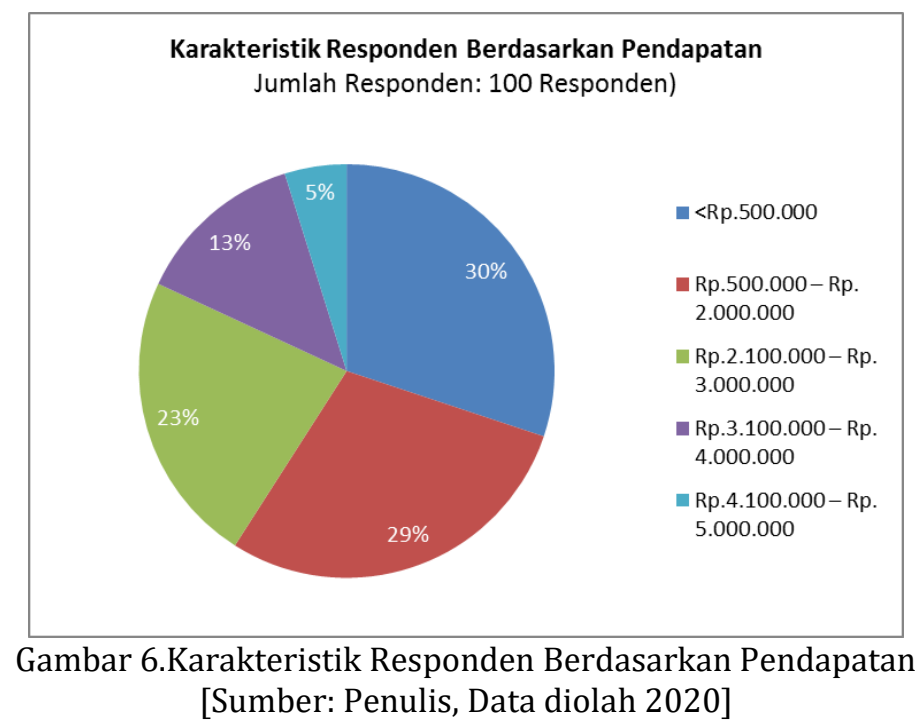

Wisatawan Kota Cirebon berasal dari berbagai kalangan dengan rentang pendapatan $<$ Rp.500.000 hingga >Rp.5.000.000. Namun, wisatawan yang mendominasi berpendapatan $<$ Rp.500.000 sebanyak 25\% dan berpendapatan Rp. 500.000 - Rp. 2.000 .000 sebanyak $24 \%$. 


\section{Karakteristik Responden Berdasarkan Jumlah Kunjungan ke Kota Cirebon}

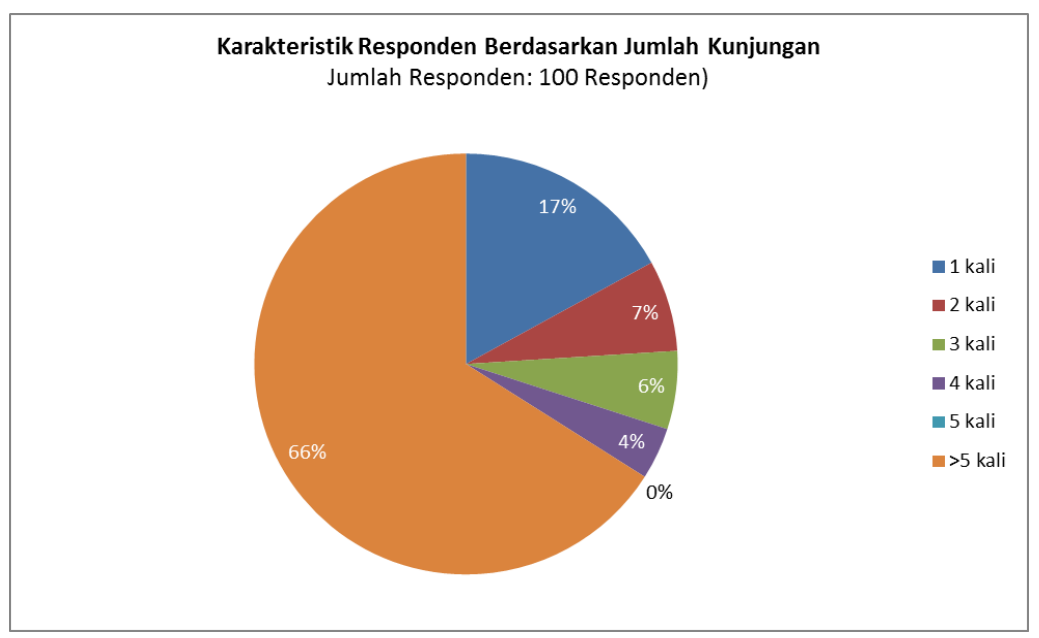

Gambar 7. Karakteristik Responden Berdasarkan Jumlah Kunjungan ke Kota Cirebon [Sumber: Penulis, Data diolah 2020]

Jumlah kunjungan wisatawan ke Kota Cirebon berbeda-beda mulai dari satu kali hingga lebih dari lima kali. Namun mayoritas wisatawan telah lebih dari lima kali berkunjung ke Kota Cirebon yaitu sebanyak 66\%. Hal tersebut dapat menjadi potensi berkembangnya wisata di Kota Cirebon karena banyak wisatawan yang melakukan kunjungan berulang ke Kota Cirebon.

\section{Karakteristik Responden Berdasarkan Tujuan Berkunjung ke Kota Cirebon}

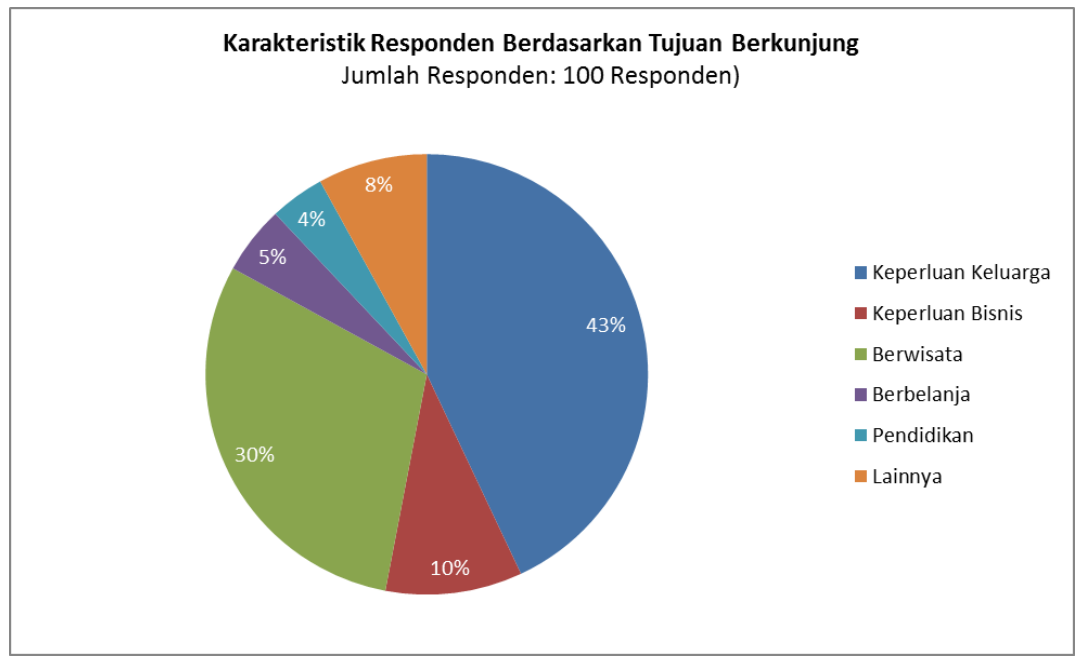

Gambar 8. Karakteristik Responden Berdasarkan Tujuan Kunjungan ke Kota Cirebon [Sumber: Penulis, Data diolah 2020]

Wisatawan berkunjung ke Kota Cirebon dengan berbagai tujuan. Sebagian besar wisatawan berkunjung dengan tujuan keperluan keluarga yaitu sebanyak 43\%. 


\section{Karakteristik Responden Berdasarkan Sumber Informasi Wisata Kota Cirebon}

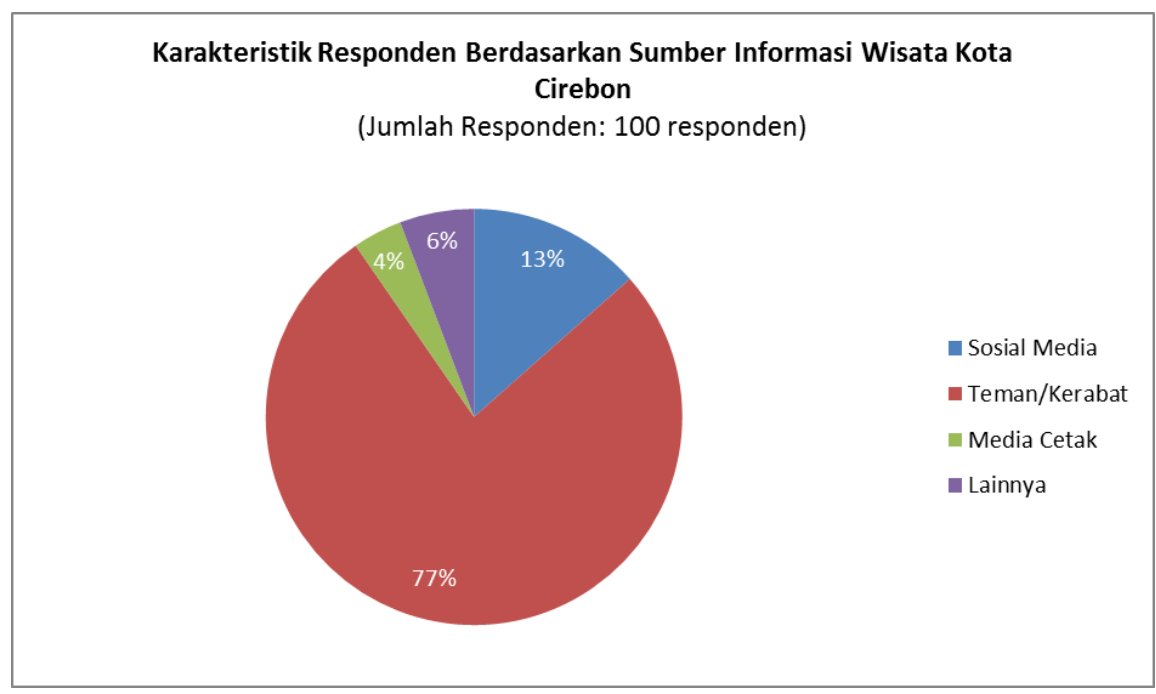

Gambar 9. Karakteristik Responden Berdasarkan Sumber Informasi Wisata Kota Cirebon [Sumber: Penulis, Data diolah 2020]

Wisatawan mendapatkan informasi seputar wisata Kota Cirebon dari berbagai sumber. Persentase terbesar adalah informasi yang didapat dari teman atau kerabat yaitu sebanyak $80 \%$. Hal tersebut menunjukkan bahwa cara yang paling efektif untuk memberikan informasi seputar wisata Kota Cirebon adalah dari mulut ke mulut.

\section{Karakteristik Responden Berdasarkan Biaya Pengeluaran Ke Kota Cirebon}

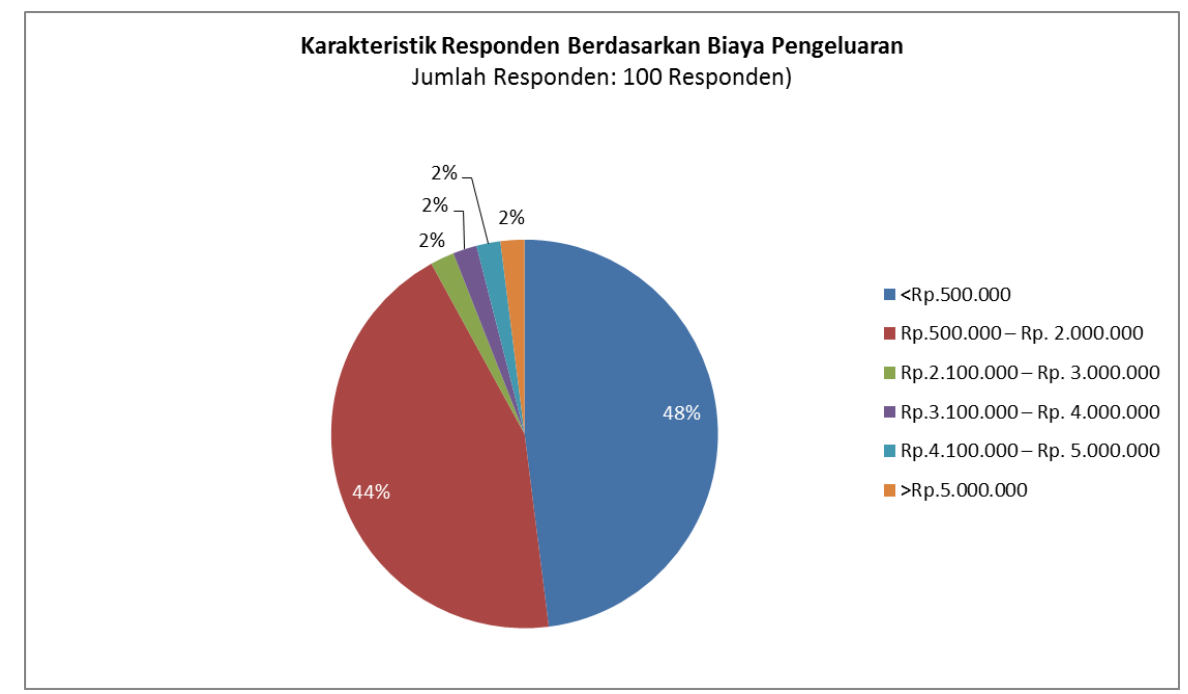

Gambar 10. Karakteristik Responden Berdasarkan Biaya Pengeluaran Ke Kota Cirebon [Sumber: Penulis, Data diolah 2020]

Menggambarkan wisatawan berkunjung ke Kota Cirebon mengeluarkan biaya yang berbeda-beda mulai dari rentang $<$ Rp.500.000 hingga $>$ Rp.5.000.000. Rata-rata wisatawan mengeluarkan biaya $<$ Rp. 500.000 yaitu sebanyak $48 \%$ dan wisatawan yang mengeluarkan biaya dengan rentang Rp. 500.000 - Rp. 2.000 .000 sebanyak 44\%. 


\section{Tempat Wisata Yang Dikunjungi Responden di Kota Cirebon}

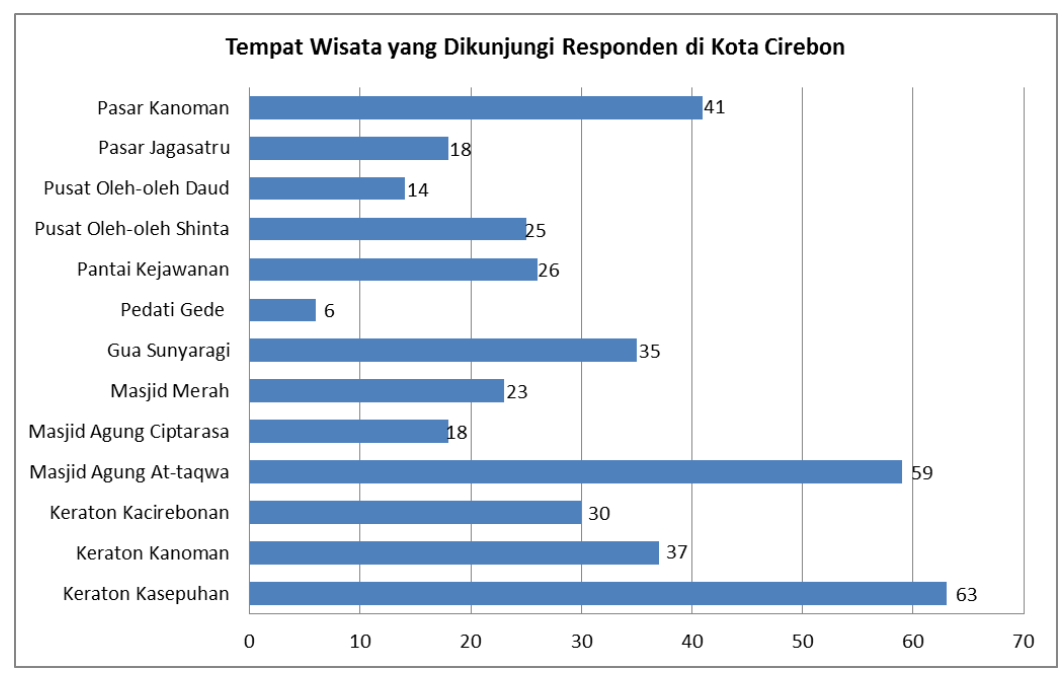

Gambar 11. Tempat Wisata yang Dikunjungi Responden di Kota Cirebon

[Sumber: Penulis, Data diolah 2020]

Wisatawan berkunjung ke berbagai tempat wisata dan pusat belanja di Kota Cirebon. Sebagian wisatawan mengunjungi Keraton Kasepuhan yaitu sebanyak 63\%, hal tersebut menunjukkan bahwa Keraton Kasepuhan merupakan salah satu tempat wisata yang cukup terkenal dan sering dikunjungi oleh wisatawan. Kemudian persentase terbesar kedua yaitu wisata Masjid Agung At-Taqwa yaitu sebanyak 59\%.

\section{Wisata Gastronomi yang Dikunjungi Responden di Kota Cirebon}

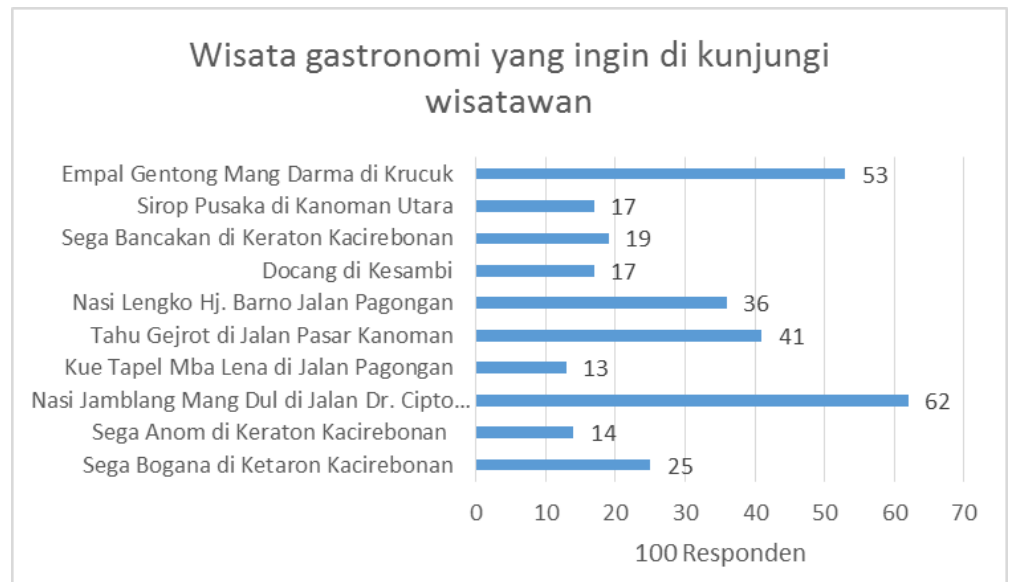

Gambar 12. Wisata Gastronomi Yang Dikunjungi Responden di Kota Cirebon

[Sumber: Penulis, Data diolah 2020]

Destinasi wisata gastronomi yang ingin dikunjungi oleh para wisatawan saat mengunjungi di Kota Cirebon. Sebanyak 63 orang ingin mengunjungi Nasi Jamblang Mang Dul yang berada di Jl. Dr Cipto Mangnkusumo hal itu menunjukan Nsi Jamblang sebagai makanan yang sangat ingin dikunjungi oleh para wisatawan kepudian diikuti oleh Empal Gentong Mang Dharma yang berada du Jl. Krucuk dan Tahu Gejrot yang berada di Jl. Kanoman atau berada dalam lingkungan Pasar Kanoman. 


\subsection{Pembahasan Hasil Wawancara dan Observasi}

\section{Model Pengembangan Gastronomi}

1) Tidak ada perubahan citarasa dan aroma pada makanan khas Kota Cirebon. Hanya saja beberapa makanan khas Kota Cirebon mengalami inovasi seperti Empal Gentong yang memiliki hasil inovasi Empal Asem.

2) Makanan khas Cirebon mengalami beberapa variasi, seperti hal nya Empal Gentong yang memiliki variasi baru yaitu Empal Asem dan lauk pauk pada Nasi Jamblang yang kian hari kiat banyak variasinya.

3) Rumah makan dan restoran yang ada di Kota Cirebon belum menerapkan aturan hygine dan sanitasi yang baik walaupun sudah memiliki aturan dari pemerintah.

\section{Upaya Stakeholder}

1) Pemerintah mengupayakan pengembangan pariwisata dari dua faktor, Faktor Internal atau faktor dari dalam badan pemerintahan, pemerintah mengupayakan pengembangan pariwisata dengan membuat pelatihan terhadap internal dan membuat konten promosi hingga membuat aplikasi pariwisata untuk wisatawan. Pemerintah melakukan pengambangan pariwisata langsung kepada pelaku pariwisata itu sendiri dengan mengadakan pelatihan terhadap pelaku usaha. Kendala dalam pengembangan pariwisata terbesar adalah Pemerintah Kta Cirebon tidak memiliki banyak destinasi wisata, pemerintah memiliki satu destinasi wisata yang dikelola oleh pihak ketiga, destinasi seperti keraton dan kesultanan milik keraton itu sendiri, kendala yang muncul lainya ada lah masalah keuangan dan pandemi.

2) Upaya pengusaha dengan mengembangkan sekor pariwisata dengan menjual apa yang dimiliki. Pengusaha menargetkan segmen pasar akan produk yang dijual nya kepada kalangan menengah keatas. Strategi yang digunakan menggunakan strategi promosi kepada media cetak hingga media siar seperti televisi dan radio, mereka juga melakukan promosi melalui media sosial.

3) Pekerja belum mengetahui apaitu 9 komponen gastronomi dan ekerja perlu di edukasi untuk mengetahui 9 komponen gastronomi guna menguasai produk yang mereka jual.

4) Pemasok tersebut sudah memulai usahanya dari tahun 2005 untuk menyupplai restoran- restoran yang ada di Kota Cirebon atau sudah berkisar 15 Tahun . pemasok mengupayakan agar bahan baku ang ada di Kota Cirebon agar selalu ada.

5) Cirebon sangat memungkinkan untuk membuat wisata gastronomi, peluang nya sangat besar dikarenakan ada beberapa keunggulan yang dimiliki Cirebon seperti kekayaan kuliner yang sangat kaya, Cirebon terletak pada Perbatasan jawa Barat dan Jawa Tengah sehingga banyak akulturasi budaya pada makanan dan budaya yang ada di Kota Cirebon. Cirebon juga memiliki Hubungan Internasinal dan Nasional yang baik sehingga hal ini sangat besar peluang nya.

6) Makanan khas Kota Cirebon mengalami perkembangan yang sangat pesat dilihat dari beberapapa makanan yang memiliki inovasi seperti Nasi Jamblang dan Empal Gentong, Nasi Jamblang memiliki banyak perkembangan pada Lauk Pauk nya, dan Empal Gentong memiliki Empal Asem sebagai hasil inovasi, makanan Kota Cirebon memiliki eksitensi yang cukup baik hingga saat ini.

7) Pendapat penikmat tentang makanan Khas Cirebon adalah citarasa ke Khasan yang terkandung dalammakanan, selain makanan nya dikenal enak, makanan tersebut dinilai otentik bagi wisatawan. Ada beberapa hal yang harus ditingkatkan seperti pelayanan dan kebersihan untuk menunjang wisata gastronomi di Kota Cirebon dan wisatawan menilai wisata gastronomi sangat baik dikarenakan halini mengedukasi wisatawan tentang suatu produk makanan yang dijual. 
8) Komunitas GenPI melakukan usaha pengenalan makanan lokal dengan cara memposting informasi makanan lokal khas Cirebon di media sosial, Komunitas GenPI juga bekerjasama dengan pihak-pihak yang mengadakan event tentang gastronomi, kendala yang dialami oleh GenPI adalah partisipan yang masih sedikit.

9) Teknologi Informasi dalam hal ini media lokal RCTV (Radar Cirebon Televisi) memilikiProgram yang bernama Icip Uyup untuk mengenalkan kepada masyarakat tentang makanan khas Cirebon. Informasi tentang pariwisata di Cirebon dapat diakses di media sosial seperti Instagram. Teknologi informasi adalah alat yang sangat penting dalam hal melakukan prpomosi hal itu dikarenakan teknologi informasi dapat diakses oleh seluruh masyarakat dengan mudah.

\section{Pola Perjalanan Wisata Gastronomi Kota Cirebon}

1) Fasilitas di Kota cirebon dapat disimpulkan dalam keadaan sangat baik, infrastruktur dan fasilitas terawat dengan baik, adapun fasilitas, fasilitas yang tersedia di Kota Cirebon seperti Tempat ibadah, petunjuk jalan bagi wisatawan hingga aplikasi untukwisatawan mengetahui destinasi wisata yang beradadi Kota Cirebon yang bernama Cirebon Wistakon.

2) Aksesibilitas yang ada di kota Cirebon tidak mengalami kendala sama sekali, transportasi umum menjangkau semua titik destinasi wisata yang ada di Kota Cirebon yang dapat dijangkau dengan mudah, semua destinasi wisata di Kota Cirebon dapat diakses oleh mobil pribadi hingga mobil bis untuk wisatawan ber skala besar.

3) Jarak antara destinasi wisata yang berada di Kota Cirebon dapat ditempuh 1530menit menggunakan mobil pribadi, wisatawan dapat menghabiskan waktu berkisar 30 menit -2 jam di setiap destinasi yang ada di Kota Cirebon.

\section{Rancangan Pola Perjalanan Wisata Kota Gastronomi}

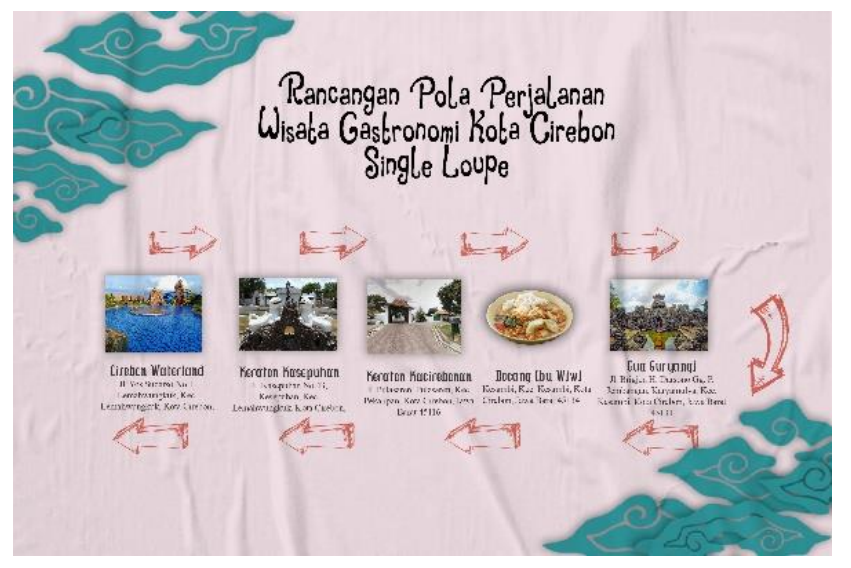

Gambar 13. Rancangan Pola Perjalanan Wisata Gastronomi Kota Cirebon Single Loupe [Sumber: Penulis,2020]

Pada pola Single Loupe Ini wisatawan akan memulai perjalanan dari Cirebon waterland atau menjadi tempat titik kumpul, lalu akan dilanjutkan menuju Keraton Kasepuhan untuk melakukan tour keraton Kasepuhan dan Masjid Agung Ciptarasa, kemudian wisatawan akan berkunjung mengunjungi Keraton Kacirebonan untuk melakukan Tour Keraton dan Melakukan Wisata Gastronomi Sega Bogana atau Sega Bancakan, setelah itu wisatawan akan mengunjungi Docang di Jl. Kesambi untuk melakukan wisata gastronomi Docang, setelah itu wisatawan melanjutkan perjalanan menuju Gua Sunyaragi untuk melakukan tour Gua dan menyaksikan pentas seni di 
kawasan Gua Sunyaragi, wisatawan akan kembali pulang melintasi Jl. Kesambi dan melintasi keraton Kacirebonan hingga tiba kembali di titik kumpul Cirebon Waterland.

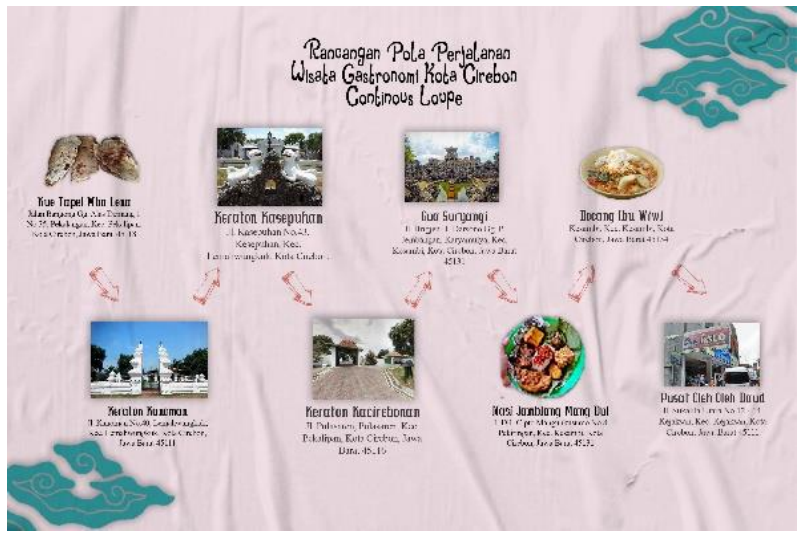

Gambar 14. Rancangan Pola Perjalanan Wisata Gastronomi Kota Cirebon Continous Loupe [Sumber: Penulis, 2020]

Pada Pola ini Wisatawan langsung mengunjungi wisata gastronomi Kue Tapel Ibu Lena di Jl. Pagongan, lalu akan mengunjungi Keraton Kanoman di Jl.Kanoman, disini wisatawan akan melakukan Tour keraton dan berbelanja hal-hal unik di pasar Kanoman yang berada tepat di depan Keraton Kanoman, wisatawan juga akan melakukan wisata gastronomi Tahu Gejrot yang berada di Pasar Kanoman, kemudian wisatawan akan mengunjungi Keraton Kasepuhan untuk melakukan Tour Keraton dan Masjid Agung Ciptarasa, Kemudian wisatawan akan mengunjungi Keraton Kacirebonan Untuk melakukan tour keraton dan melakukan wisata Gastronomi Sega Bogana/ Sega Bancakan. Kemudian wisatawan akan mengunjungi Gua Sunyaragi untuk melakukan tour Gua. Kemudian wisatawan akan melakukan perjalanan Wisata Gastronomi Nasi Jamblang di Nasi Jamblang Mang Dul Jl. Gunungsari, kemudian wisatawan akan mengunjungi Pusat Oleh-oleh Daud, yang terakhir akan mengunjungi wisata Gastronomi Docang di Jl.Kesambi, pola ini tidak mengantar wisatawan kembali ke titik kumpul.

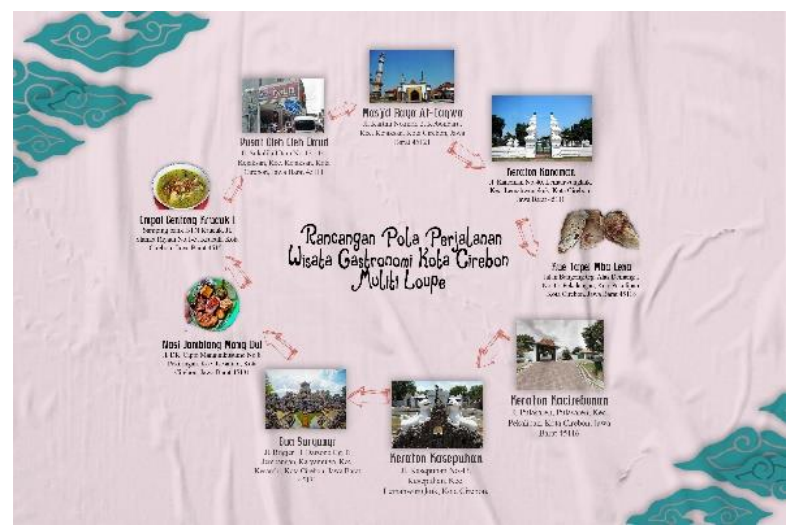

Gambar 15. Rancangan Pola Perjalanan Wisata Gastronomi Kota Cirebon Multi Loupe [Sumber: Penulis,2020]

Pada pola ini wisatawan akang berada di titik kumpul Masjid Raya At-taqwa dan akan kembali ke titik kumpul dengan tidak melewati destinasi yang sudah dikunjungi nya, setelah pertama wisatawan akan mengunjungi keraton kanoman, disini wisatawan akan melakukan Tour Keraton dan dapat berbelanja pasar tradisional Kanoman yang 
bertempat tepat didepan Keraton Kanoman, wisatawan juga bisa melakukan wisata gastronomi Tahu Gejrot yang berada di Jl. Kanoman, Kemudian wisatawan mengunjungi Kue Tapel Ibu Lena yang berada di Jl. Pagongan setelah itu wisatawan mengunjungi Keraton Kacirebonan disini wisatawan bisa melakukan tour Keraton dan melakukan wisata Gastronomi Sega Bogana dan Sega Bancakan, setelah itu wisatawan akan mengunjungi Keraton Kasepuhan disini wisatawan bisa melakukan Tour Keraton dan Masjid Agung Ciptarasa kemudian wisatwan mengunjungi Gua Sunyaragi disini wisatawan dapat melakukan tour Gua dan selanjutnya wisatawan mengunjungi Nasi Jamblang Mang Dul yang berada di Jl.Gunungsari, kemudian wisatawan akan mengunjungi Empal Gentong Krucuk di Jl. Krucuk, selanjutnya wisatawan akan melakukan perjalanan ke pusat oleholeh Daud sebelum akhirnya kembali ke titik Kumpul di Masjid Agung At-Taqwa.

\section{KESIMPULAN}

Karakteristik wisatawan Kota cirebon didonminasi oleh Perempuan dan wisatwan terbesar berasal dari Majalengka dan Bandung, wisatawan lebih memilih untuk berwisata menggunakan kendaraan pribadi dan mengunjungi destinasi-destinasi yang sudah banyak dikenal oleh wisatawan, wisatawan mendapatkan informasi tentang berwisata di kota cirebon berasal dari Keluarga dan media sosial, dan megunjungi Kota Cirebon dikarenakan kepentingan awal Keperluan keluarga, hampir seluruh wisatawan sudah mengunjungi kota Cirebon lebih dari satu kali, wisatawan yang berkunjung ke Kota Cirebon sebagian besar adalah para mahasiswa, ASN hingga pengusaha . yang memiliki pendapatan bervariasi dari Rp 500.000 hingga lebih dari Rp 5.000.000 dan wisatawan mengeluarkan biaya di kota Cirebon bervariasi mulai kurang dari Rp 500.000 hingga lebih dari Rp 5.000.000 pada saat mengunjungi kota Cirebon. Rata rata wisatwan mengeluarkan biaya kurang dari Rp 500.000 .

Daya Tarik dikenal dengan wisatawan dengan wisata yang berbasis oleh Kesultanan yang berada di Kota Cirebon, Hal itu dikarenakan ada 3 kesultanan yang berada langsung di Kota Cirebon yaitu Keraton Kasepuhan, Keraton Kanoman, dan keraton termuda yaitu Keraton Kacirebonan. Hal itu mengakibatkan beberapa makanan memiliki unsur kesultanan dari sejarah hingga cara menikmati makanan tersebut.

Makanan Khas kota Cirebon kini sedang mengalami kenaikan eksistensi, beberapa makanan mulai berinovasi mengikuti perkembangan yang ada, makan khas Kota Cirebon sudah memiliki 9 komponen gastronomi yang cukup untuk dijadikan program Wisata Gastronomi di Kota Cirebon. Kota Cirebon sangat berpotensi mengadakan Wisata Gastronomi dikarenakan nilai budaya seperti sejarah makanan itu terbentuk dan cerita dibalik proses pembuatan yang terkandung pada makanan lokal itu sendiri dan ketersidaan fasilitas yang mendukung untuk diadakan Wisata Gastronomi di Kota Cirebon.

Peran stakeholder dalam melakuakan kordinasi untuk meningkatkan pariwisata yang ada di kota cirebon harus lebih maksimal, hal itu dikarenakanmasih kurang nya kordinasi antara pemerintah danpemilik destinasi wisata dalam hal ini pihak keraton yang mengelola destinasi kepemilikan nya sendiri, kerjasama antar stakeholder pariwisata sangat dibutuhkan karena pariwisata tidak bisa berdisi sendiri. Selain itu pemerintah juga sudah mengadakan pelatihan atau penyuluhan kepada pelaku-pelaku pariwisata yang terlibat, komunitas sudah memiliki program dalam Tv lokal untuk mempromosikan makanan khas yang ada di Kota Cirebon.

Mengenai perencanaan pola perjalanan wisata gastronomi di Kota Cirebon fasilitas dan infrastruktur dalam keaadaan baik dan tidak ada kendala dalam hal aksesibilitas dan didapatkan tiga pola perjalanan wisata gastronomi yang dapat di implementasikan kepada wisatawan jika mengunjungi Kota Cirebon yaitu pola single loupe, continous loupe, dan multi loupe. 


\section{DAFTAR PUSTAKA}

Andriani. S, N. N., \& Hadi, A. P. (2018). Pola Perjalanan Wisatawan Timur Tengah Berdasarkan Profil Wisatawan Dan Motivasi Pola Pergerakan Di Bandung. National Conference of Creative Industry, (October). https://doi.org/10.30813/ncci.v0i0.1252

Ahmad, R. (2015). Efektivitas Segmentasi Pasar Wisatawan. Retrieved from https://ahmadrimba.wordpress.com/2015/06/03/efektivitassegmentasipasarwisatawan/

Badan Pusat Statistik. (2016). Kota dan Kabupaten Jawa Barat Dalam Angka 2016. Jawa Barat: Badan Pusat Statistika Jawa Barat.

Basoeki, A. (2014). Materi Seminar Pola Perjalanan Indonesia. Bandung.

Disporbudpar (2018) Wisatawan Kota Cirebon Dalam Angka 2013-2017.

Djarwanto. (1994). Pokok-Pokok Metode Riset dan Bimbingan Teknis Penulisan.Skripsi. Yogyakarta: Liberty.

Guba, E.G \& Lincoln Y.S, (1981). Effektif Evaluation. Improving The Usefulness of Evaluations Result Through Responsive And Naturalistic Approaches. Jassey-Bass Inc. Publisher

Hetifah, Sj. (2003). Inovasi, Partisipasi dan Good Governance. Bogor: Yayasan Obor Indonesia.

Imelda, J. (2015). Laporan Dialog Gastronomi Nasional.

Ismayati. (2010). Pengantar Pariwisata. Jakarta: Grasindo.

Kristanto, A. (2018). Perancangan Sistem Informasi Dan Aplikasinya. Yogyakarta

Komariah, A. \& Djama'an, S. (2014). Metedologi Penelitian Kualitatif. Bandung: Alfabetha

Mansueto, J. (2005). Pengurusan Teknologi : University Teknologi Malaysia.

Meolong, L. J. (2007). Metodelogi Penelitian Kualitatif. Bandung: PT Remaja Rosdakarya Offset.

Muljadi, A. J. \& Warman, A. (2014). Kepariwisataan dan Perjalanan. Jakarta: Rajagrafindo Persada

Mulyani, A. \& Wirakusuma, R. M. (2016). Perencanaan Paket Wisata Berdasarkan Karakteristik dan Motivasi Wisatawan yang Datang ke Kampung Cireundeu Kota Bandung. Jurnal Manajemen Resort dan Leisure. 13(2).

Nafisah, S. (2003). Pengertian Perencanaan. http://rumohkuta.blogspot.com/2013/02/Pengertian-perancangan.html diakses pada 20 Deseber 2019

Nuriata, T. (2014). Perencanaan dan Pelaksanaan Perjalanan Wisata. Bandung: Alfabeta.

Nurwitasari, A. (2015). Pengaruh Wisata Gastronomi Makanan Tradisional Sunda Terhadap Keputusan Wisatawan Berkunjung Ke Kota Bandung. Barista, 2(1), 92102.

Pendit, N. S. (1994). Ilmu Pariwisata: Sebuah Pengantar Perdana. Jakarta: Pradnya Paramita.

Pérez G. J. C., López-Guzmán, T., Buiza, F. C., \& Medina-Viruel, M.J. (2017). Gastronomy as an element of attraction in a tourist destination: the case of Lima, Peru. Journal of Ethnic Foods, 4(4), 254-261. https://doi.org/10.1016/j.jef.2017.11.002

Plog, S.C. (1972). Why Destination Areas Rise and Fallin Popularity. Cornell Hotel and Restaurant Association Quarterly 14(3): 13-16.

Pressman, R. (2012). Rekayasa Perangkat Lunak. Yogyakarta : Andi.

Rahim, A. G., dkk. (2012). The Influence of Product Attributes on Consumer Purchase Decision in the Nigerian Food and Beverage Industry: A Study of Lagos Metropolis. American Journal of Business and Management. 1(4). 196-201.

Rao, H., Monin, P., \& Durand, R. (2003). Institusional change in toque ville: Nouvelle cuisine as an identity movement in French gastronomy. American Journal of Sociology, 108(4), 795-843+i. https://doi.org/10.1086/367917 
Richardson, J. I., \& Flucker, M. (2004). Understanding and managing Tourism. Pearson Education Australia

Roebuck, J. A. (1995). Anthropometric Methods : Designing to Fit the Human Body, Human Factors and Ergonomics Society. USA.

Salah, W. (1975). Tourism Management. London: Tourism International Press.

Santich, B. (2004). The study of gastronomy is relevance to hospitality education and training. Internationa Journal of Hospitality Management. 23(1), 15-24.

Schmoll, G.A. (1997). Tourism Promotion: Marketing Background, Promotion Techniques and Promotion Planning. London: Tourism Intenational Press

Semiawan, C. R. (2010). Metode Penelitian Kualitatif. Jakarta: Grasindo.

Soekadijo, R, G. (2000). Anatomi Pariwisata Memahami Pariwisata sebagai systrmic linkage. Jakarta: PT.Gramedia Pustaka Utama.

Suryadana, \& Octavia, V. (2015). Pengantar Pemasaran Pariwisata. Bandung: Alfabeta.

Taqwani, D.M. (2012). Analisis Kebudayaan Gastronomi Dan Tindak Tutur Dalam Kajian Pragmatik Pada Film Ratatouille, 55.

Turgarini, D., \& Pridia R. Sari. H. (2016). Gastronomy Tourism Attraction in Ternate City. 28(Ictgtd 2016), 90-96. https://doi.org/10.2991/ictgtd- 16.2017.17

Turgarini, D. (2014). Inventory Of Gastronomy Tradition And Philosophy As Database Indonesia Tourism.

Turgarini, D. (2018). Gastronomi Sunda Sebagai Daya Tarik Wisata Kota Bandung. Universitas Gadjah Mada, Yogyakarta.

Undang-Undang Republik Indonesia Nomor 10 tahun 2009 Kepariwisataan.

Utama, I. G. B., \& M, N. M. E. (2012). Metodologi Penelitian Pariwisata dan Perhotelan. Yogyakarta: CV Andi. 